\title{
miR-29b defines the pro-/anti-proliferative effects of S100A7 in breast cancer
}

\author{
Helong Zhao ${ }^{\dagger}$, Tasha Wilkie ${ }^{\dagger}$, Yadwinder Deol, Amita Sneh, Akaansha Ganju, Mustafa Basree, Mohd W Nasser \\ and Ramesh K Ganju*
}

\begin{abstract}
Introduction: S100A7 (Psoriasin) is an inflammatory protein known to be upregulated in breast cancer. However, the role of S100A7 in breast cancer has been elusive, since both pro- and anti-proliferative roles have been reported in different types of breast cancer cells and animal models. To date, the mechanism by which S100A7 differentially regulates breast cancer cell proliferation is still not clear.
\end{abstract}

Methods: We used Gene Functional Enrichment Analysis to search for the determining factor of S100A7 differential regulation. We confirmed the factor and elaborated its regulating mechanism using in vitro cell culture. We further verified the findings using xenografts of human breast cancer cells in nude mice.

Results: In the present study, we show that S100A7 significantly upregulates the expression of miR-29b in Estrogen Receptor (ER)-positive breast cancer cells (represented by MCF7), and significantly downregulates miR-29b in ER-negative cells (represented by MDA-MB-231). The differential regulation of miR-29b by S100A7 in ER-positive and ER-negative breast cancer is supported by the gene expression analysis of TCGA invasive breast cancer dataset. miR-29b transcription is inhibited by NF-KB, and NF-KB activation is differentially regulated by S100A7 in ER-positive and ER-negative breast cancer cells. This further leads to differential regulation of PI3K p85a and CDC42 expression, p53 activation and p53-associated anti-proliferative pathways. Reversing the S100A7-caused changes of miR-29b expression by transfecting exogenous miR-29b or miR-29b-Decoy can inhibit the effects of S100A7 on in vitro cell proliferation and tumor growth in nude mice.

Conclusions: The distinct modulations of the NF-KB - miR-29b - p53 pathway make S100A7 an oncogene in ER-negative and a cancer-suppressing gene in ER-positive breast cancer cells, with miR-29b being the determining regulatory factor.

Keywords: Breast cancer, Cell proliferation, S100A7, miR-29b, p53

\section{Introduction}

The inflammatory protein S100A7 (Psoriasin) was discovered as a marker of human psoriasis lesion [1,2]. S100A7 is mainly expressed in epithelial cells [2], and can be induced by pathogens and inflammatory cytokines [3,4]. It has been noticed that S100A7 is upregulated in breast cancer cells [5-7]. However, the role of S100A7 in breast cancer progression has been elusive, since both pro- and anti-proliferative roles have been reported in different types of breast cancer cells and animal models [8-11]. It has been shown that S100A7 promotes cancer growth and

\footnotetext{
* Correspondence: Mohd.Nasser@osumc.edu; Ramesh.Ganju@osumc.edu ${ }^{\dagger}$ Equal contributors

Department of Pathology, The Ohio State University Wexner Medical Center, 840 BRT, 460W 12th Ave, Columbus, OH 43210, USA
}

metastasis in basal-like $\left(\mathrm{ER}^{-}\right)$breast cancer cells $[10,12]$. Accordingly, S100A7 upregulation correlates with poor prognosis for patients with basal subtype breast carcinoma [9]. Conversely, it inhibits cancer growth and cell migration in luminal $\left(\mathrm{ER}^{+}\right)$breast cancer cells [8]. To date, the mechanism by which S100A7 differentially regulates $E^{-}$ and $\mathrm{ER}^{+}$breast cancer cell proliferation is unknown.

microRNAs bind to untranslated regions (UTRs) of mRNAs, which inhibits protein translation and/or degrades mRNAs [13]. miR-29b is considered to be a tumor suppressor in multiple types of cancers $[14,15]$, including breast cancer $[16,17]$. The anti-cancer effect of miR-29b has been shown to be related to its targeting of the 3' UTRs of multiple key cancer regulators, thus suppressing the growth and metastasis of breast cancer. miR-29b is encoded by two 
genes, mir-29b-1 on chromosome 7 and mir-29b-2 on chromosome 1 . It has been shown that NF-kB binds to the promoter of mir-29b-1 and inhibits its transcription [18]. In addition, NF- $\mathrm{B}$ has been shown to transactivate YY1, which then binds to the promoter of mir-29b-2 and inhibits its transcription [19]. Since NF-кB governs numerous survival genes and apoptotic genes, its functions in cancer development has long been noted. The activity of NF-kB can be either upregulated or downregulated in cancer cells, depending on whether it is inducing survival signaling or apoptotic signaling [20]. The differential activation statuses of NF- $\mathrm{kB}$ in different breast cancer subtypes has led to the discovery of reciprocal regulation of NF-kB by ER [21].

Among the targets of miR-29b, PI3K p $85 \alpha$ and CDC42 have been shown to regulate p53 activation [22]. Activated p53 translocates into the nucleus and activates multiple anti-proliferative pathways, including the ones of DNA repair and mitosis check point [23]. It was shown that miR-29b targets $\mathrm{p} 85 \alpha$ and $\mathrm{CDC} 42$ and consequently inhibits p53 activation and cell proliferation [22].

In the present study, we described a novel role of the NF-kB - miR-29b - p53 pathway, which defines the distinct effects of S100A7 on regulating cell proliferation and tumor growth of $\mathrm{ER}^{-}$and $\mathrm{ER}^{+}$breast cancer.

\section{Results}

S100A7 differentially regulates proliferation of $E R^{-}$and $E R^{+}$ breast cancer cells

To investigate the effect of S100A7 upregulation in human breast cancer, we generated a panel of S100A7 overexpressing breast cancer cell lines $[8,10]$. S100A7 overexpression significantly increased the proliferation of $\mathrm{ER}^{-} \mathrm{MDA}-\mathrm{MB}-$ 231 cells and decreased that of ER ${ }^{+}$MCF7 cells (Table 1 ). Furthermore, with S100A7 overexpression, MDA-MB-231 cells gained mesenchymal properties (fibroblast-like cell shape and absence of cell-cell adhesion) and increased tumor growth in nude mice; in contrast, with S100A7 overexpression, MCF7 cells gained epithelial properties (flat scale-like cell shape and increased cell-cell adhesion) and showed reduced tumor growth in nude mice (Table 1). These observations are in accordance with previous publications from our group and others $[8,10,12]$. In this study, we used MDA-MB-231 and MCF7 as representative cellular models of $\mathrm{ER}^{-}$and $\mathrm{ER}^{+}$breast cancers to analyze the mechanism by which S100A7 may differentially regulate cell proliferation.

\section{S100A7 overexpression induced differential miR-29b expression changes in MDA-MB-231 and MCF7 cells}

In order to analyze the mechanism by which S100A7 differentially regulates cell proliferation, we characterized the gene expression signatures in the microarray data of S100A7 overexpressing MDA-MB-231 and MCF7 cells (231-S100A7 and MCF7-S100A7). We postulated that we would pinpoint the driving factor of proliferative regulation by comparing the differential imprints of S100A7 overexpression in the transcriptomes of MDA-MB-231 and MCF7 cells. To do this, we performed the Gene Functional Enrichment (GFE) analysis to the microarray data of 231-V/231-S100A7 and MCF7-V/MCF7-S100A7 cells with the bioinformatic engine, ToppGene. We used the genes which were up-/down-regulated greater than 2 folds in 231-S100A7 (v.s. vector control) and a comparable number of genes which were up-/down-regulated greater than 2.5 folds in MCF7-S100A7 (v.s. vector control) as training sets for randomized separate GFE analysis. We then compared the GFE analysis outcomes of these four sets and discovered a common imprint between MDAMB-231 and MCF7 that is associated with opposite changes of genes: the expression changes of miR-29b targets. As shown in Figure 1A, miR-29b target genes were significantly enriched in the genes upregulated in 231S100A7 and also in those downregulated in MCF7S100A7 cells. miR-29b has been considered a strong tumor suppressor in multiple cancers. Based on the fact that miR-29b target genes were upregulated in 231S100A7 and downregulated in MCF7-S100A7 cells, we hypothesized that S100A7 differentially regulates miR-29b expression which subsequently affects cell proliferation in MDA-MB-231 and MCF7 cells through modulation of miR-29b target genes. In order to verify this, we first analyzed the expression levels of both mature miR-29b and its two primary microRNAs on chromosome 7 and 1 . In agreement with our GFE analysis, we observed that S100A7 overexpression significantly downregulated miR29b expression in MDA-MB-231 cells and upregulated

Table 1 Differential effects of S100A7 overexpression in human breast cancer cell lines

\begin{tabular}{|c|c|c|}
\hline Cell line & MDA-MB-231 & MCF7 \\
\hline Cancer subtype & Basal-like & Luminal \\
\hline ER status & ER negative & ER positive \\
\hline Proliferation change with S100A7 overexpression & $\uparrow 57 \% *$ & $\downarrow 33 \% *$ \\
\hline Morphology change with S100A7 overexpression & Gained mesenchymal & Gained epithelial \\
\hline Tumor growth with S100A7 overexpression & $\uparrow 1089 \% *$ & $\downarrow 79 \% *$ \\
\hline
\end{tabular}

Changes of cell proliferation, morphology, tumor formation in nude mice caused by S100A7 overexpression in given cell lines are listed. Mesenchymal properties of cell morphology include fibroblast-like cell shape, absence of cell-cell adhesion; epithelial properties include flat and scale-like cell shape, increased cell-cell adhesion and clustering. ( $\left.{ }^{*} \mathrm{p}<0.05\right)$. 


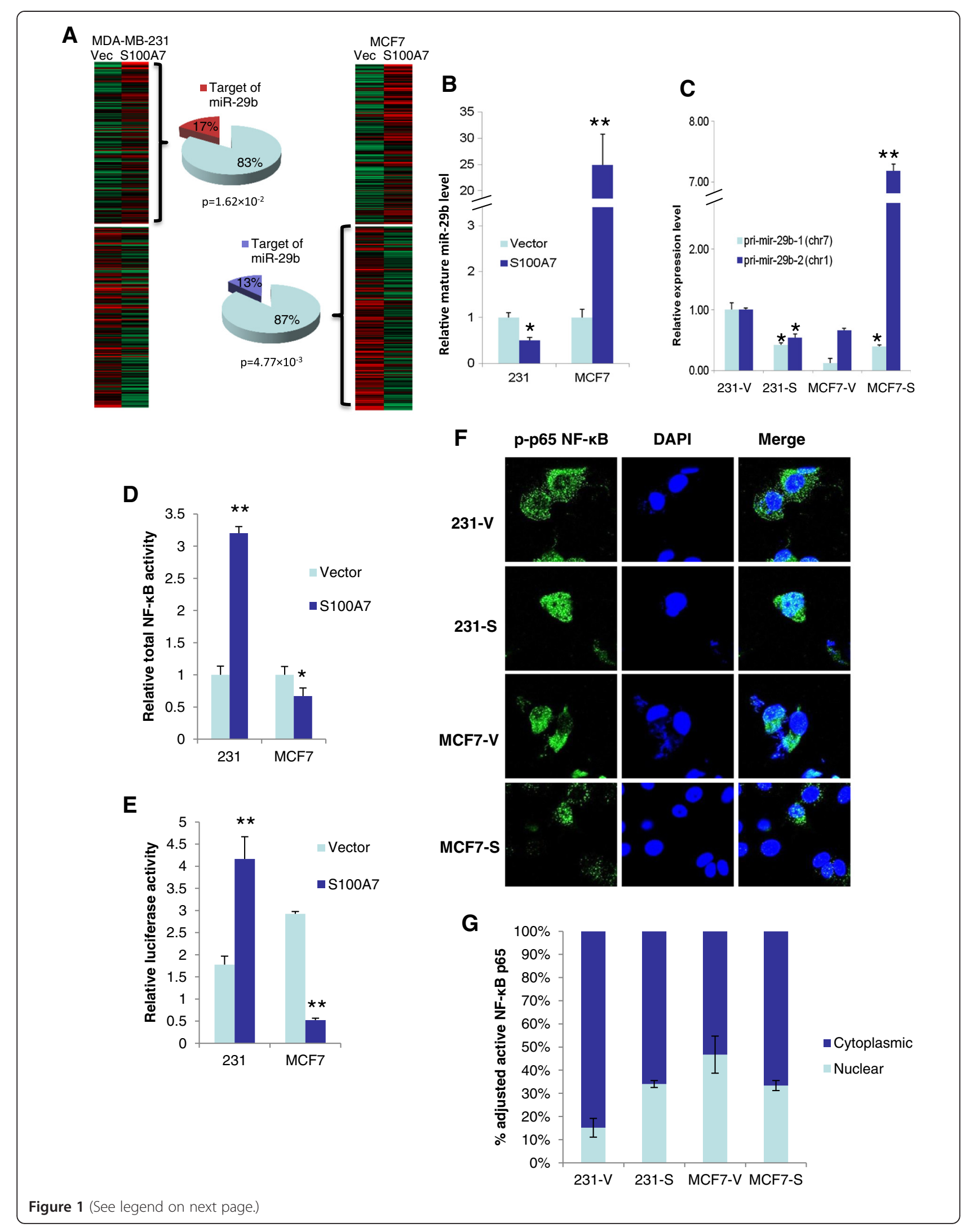


(See figure on previous page.)

Figure 1 S100A7 differentially regulates miR-29b transcription and NF-KB activation in MDA-MB-231 and MCF7 cells. (A) GFE analysis was performed on the top up/down-regulated genes of 231-S100A7 and MCF7-S100A7 cells. Genes up/down-regulated > 2 folds in 231-S100A7 and those up/down-regulated > 2.5 folds (similar amounts of genes) in MCF7-S100A7 were filtered from microarray data and used as training sets for separate analysis. Training sets from microarray data are indicated by heat maps, and percentage of miR-29b targets are indicated with pie charts with significance of enrichment analysis. (B) mature miR-29b was measured by qRT-PCR in the given cell lines, with RNU6B as internal control. Values are not comparable between MDA-MB-231 and MCF7 cells. (C) primary mir-29b-1 and mir-29b-2 transcript levels were detected by qRT-PCR using specific primers. 18S rRNA was used as internal control. (D) total cell lysates were subjected to KB-site-DNA-bait ELISA assay to detect total active NF-KB dimer level. Values are not comparable between MDA-MB-231 and MCF7 cells. (E) cells transfected with NF-kB reporter plasmids were harvested after 48 h, luciferase activity was analyzed in cell lysates. (F) activated p-p65 subunit of NF-KB in different cells were observed with confocal microscopy. Nuclei were stained with DAPI. (G) nuclear and cytoplasmic portions of cells were extracted and activated p65 NF-kB were detected with KB-site-DNA-bait ELISA. Data show the relative percentage of active NF-KB in the two portions. $\left({ }^{*} p<0.05,{ }^{* *} p<0.01\right)$.

miR-29b in MCF7 cells, in both mature (miR-29b) and primary (pri-mir-29b-1 and pri-mir-29b-2) forms (Figure 1B, C). Importantly, in agreement with our in vitro cell line data (Figure 1B, C), analysis of TCGA invasive breast cancer patient data [24] showed that S100A7 overexpression in $\mathrm{ER}^{+}$patients is more likely to correlate with miR-29b upregulation than $\mathrm{ER}^{-}$patients; and S100A7 overexpression in $\mathrm{ER}^{-}$patients is more likely to correlate with miR-29b downregulation than $\mathrm{ER}^{+}$patients (Additional file 1: Figures S1, S2 and S3). These data showed that S100A7 differentially regulates miR-29b transcription in $\mathrm{ER}^{-}$and $\mathrm{ER}^{+}$breast cancers.

\section{S100A7 differentially modulates NF-KB activation in MDA- MB-231 and MCF7}

Interestingly, we observed differential regulation of $\mathrm{NF}-\mathrm{kB}$ activity by S100A7, which is similar to the differential regulation of miR-29b expression in MDA-MB-231 and MCF7 cells. Using both $\kappa B$-site-DNA-bait ELISA and NF$\kappa \mathrm{B}$-luciferase reporter assay, we observed an increase of NF- $\kappa$ B activity in MDA-MB-231 and a decrease of NF- $\kappa B$ activity in MCF7 after S100A7 overexpression (Figure 1D, E). $\kappa B$-site-DNA-bait ELISA detected the overall activated p65 NF-kB level, and NF-kB-luciferase reporter assay detected the actual transcription driving NF- $\mathrm{B}$ level. Similar to changes in NF- $\mathrm{kB}$ activation level, we also observed increased NF- $\mathrm{kB}$ nuclear translocation in MDA-MB-231 and decreased NF- $\mathrm{KB}$ nuclear translocation in MCF7 after S100A7 overexpression (Figure 1F, G).

\section{miR-29b transcription is differentially regulated by S100A7 via NF-KB in MDA-MB-231 and MCF7}

miR-29b expression has been shown to be inhibited by NF$\kappa \mathrm{B}$ in non-breast cancer cells $[18,19,25]$. We intended to find out whether S100A7 affected miR-29b transcription via regulating $\mathrm{NF}-\mathrm{kB}$ activation in MDA-MB-231 and MCF7. We first verified that, in breast cancer cells, inhibiting NF- $\mathrm{B}$ activation with its inhibitor, QNZ, significantly enhanced the transcription of pri-mir-29b-1 and pri-mir29b-2 (Figure 2A). This showed that NF-kB activity was inversely correlated with miR-29b transcription in breast cancer cells. pri-mir-29b-1 promoter contains three NF-kB binding sites. The binding of NF-kB to the promoter directly suppresses pri-mir-29b-1 transcription (Figure 2B). In addition, NF- $\kappa \mathrm{B}$ transactivates the transcriptional factor, YY1, which in turn can bind to the promoter of pri-mir29b-2 to suppress its transcription (Figure 2C). By ChIP assay and qRT-PCR, we observed that S100A7 overexpression differentially altered the binding of NF- $\mathrm{BB}$ to the promoter of pri-mir-29b-1 and/or the expression of primir-29b-2 suppressor, YY1, in MDA-MB-231 and MCF7 cells (Figure 2D-F). Both direct and indirect transcriptional regulations by NF-kB led to the differential regulation of miR-29b levels by S100A7, in MDA-MB-231 and MCF7 cells.

\section{S100A7 downregulates PI3K p85a and CDC42 via targeting of miR-29b to activate and stabilize p53 in MCF7}

It has been reported that miR-29b activates p53 through targeting the 3' UTR of the oncogenes, PI3K p $85 \alpha$ and CDC42 [22] (Figure 3A). Activated (phosphorylated) p53 translocates into nucleus and is protected from degradation in the cytoplasm (stabilized). We showed that S100A7 induced upregulation of miR-29b in MCF7 cells was able to reduce the level of $\mathrm{p} 85 \alpha$ and CDC42 proteins (Figure 3B). Transient knockdown of miR-29b with miR-29b inhibitor (antagomir) partially rescued the expression of $\mathrm{p} 85 \alpha$ and CDC42 (Figure 3C, D). Prolonged knock down of miR-29b by miR-29b-Decoy transfection reduced p53 activation in MCF7-S100A7 (Figure 3E). Compared to MDA-MB-231, S100A7 caused a much more dramatic change of miR-29b in MCF7 cells (Figure 1B). This dramatic rise of miR-29b led to a significant increase of p53 phosphorylation, nuclear translocation (Figure 3E-G, Additional file 1: Figure S4) and total p53 protein level (Figure 3H) in MCF7-S100A7 cells.

\section{S100A7 enhances p53 related anti-proliferative pathways in MCF7}

We further investigated the mechanism by which S100A7 inhibited MCF7 proliferation. p53 pathway qRT-PCR array data revealed that S100A7 overexpression in MCF7 cells led to the upregulation of p53 activating factors (such as 

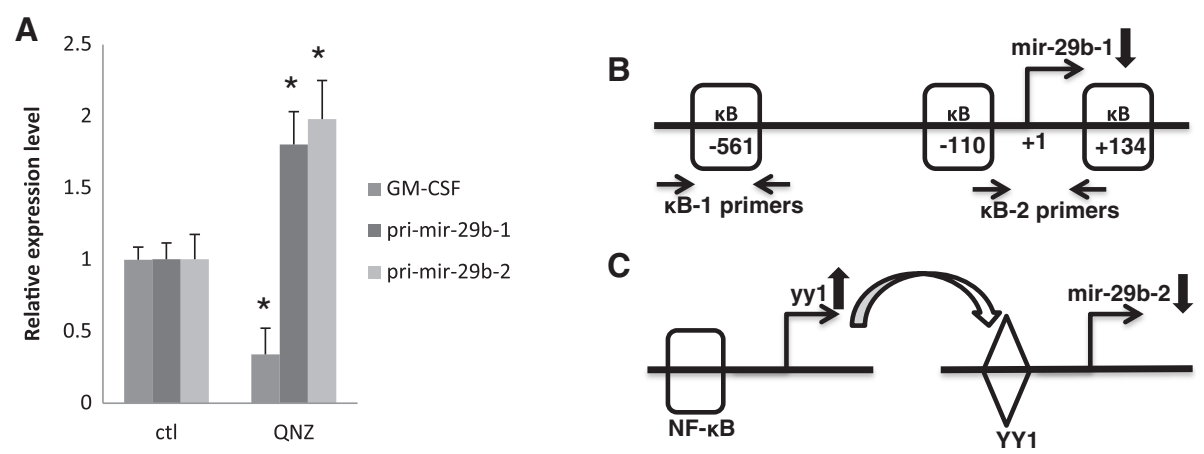

C
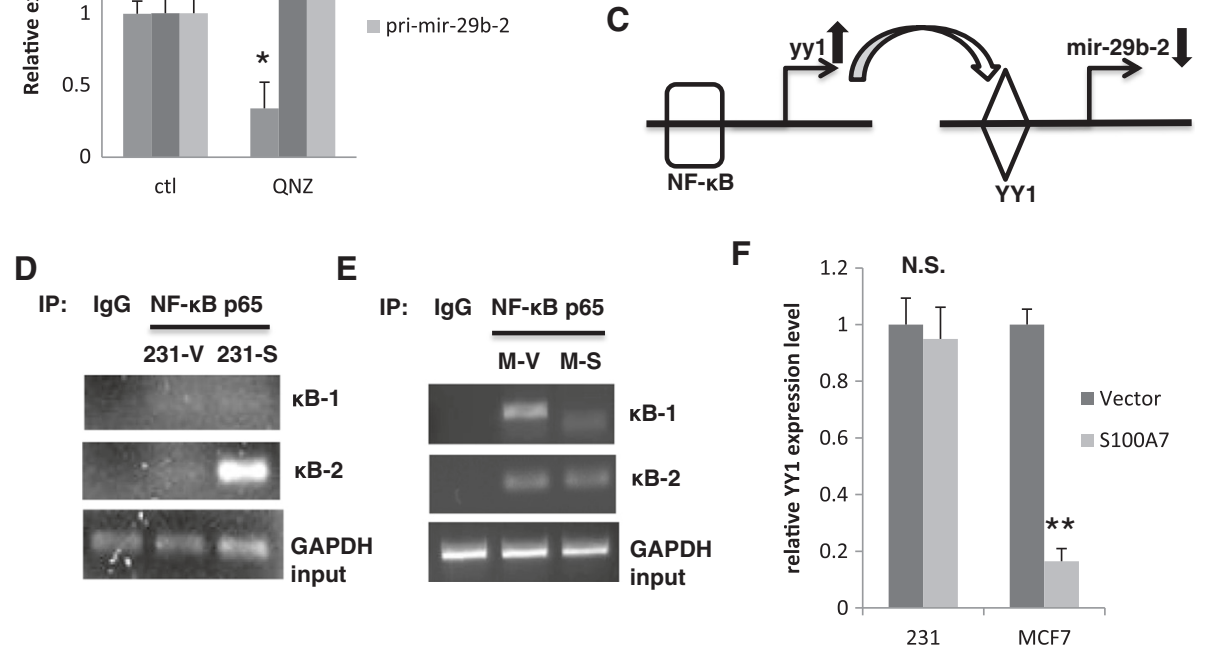

Figure 2 S100A7 differentially regulates miR-29b transcription in MDA-MB-231 and MCF7 cells. (A) MCF7 cells were treated with 5nM QNZ for $24 \mathrm{~h}$ before they were harvested for qRT-PCR analysis. A well-known NF-KB driven gene GM-CSF served as the positive control for effect of QNZ inhibition. (B) $\mathrm{KB}$ binding sites at the proximal of mir-29b-1 gene transcriptional start site. Two sets of primers, $\mathrm{KB}-1$ and $\mathrm{KB}-2$, were designed to detect three $\mathrm{KB}$ binding sites in ChIP. (C) indirect inhibition of mir-29b-2 transcription by NF-KB and YY1. (D) ChIP assay of NF-KB p65 subunit binding to mir-29b-1 promoter region in 231-V and 231-S cells. (E) ChIP assay of NF-KB p65 subunit binding to mir-29b-1 promoter region in MCF7-V (M-V) and MCF7-S (M-S). (F) qRT-PCR quantification of YY1 level in different cells. ( ${ }^{*} p<0.05,{ }^{* *} p<0.01$, N.S.: non-significant).

ATM, ATR, CDKN1A/p21, CDKN2A and CHEK2), p53 targeted apoptotic factors (such as FAS and TNFRSF10B), p53 targeted DNA repairing factors (such as PCNA and PTTG1) and p53 targeted anti-survival factors (such as PTEN) (Figure 4A). Consequently, DNA repair pathway in MCF7-S100A7 cells was also activated through p53. Phosphorylation of ATR, Chk-1 and Chk-2 was enhanced by $\mathrm{S} 100 \mathrm{~A} 7$, which was absent when $\mathrm{p} 53$ is knocked down in MCF7 cells [26] (Figure 4B, C). S100A7 induced p53 upregulation appeared to be concurrently related with significantly enhanced anti-proliferative pathways in MCF7 cells.

\section{S100A7 induced differential regulation of miR-29b is important for its differential effects on cell proliferation of MDA-MB-231 and MCF7 in vitro and their tumor growth in vivo}

To verify the importance of miR-29b in determining the differential effects of S100A7, we stably transfected 231S100A7 and MCF7-S100A7 cells with exogenous miR-29b and miR-29b-Decoy, respectively, to reverse the changes of miR-29b caused by S100A7 (Figure 5A, C). The S100A7 induced proliferation increase in MDA-MB-231 was repressed by exogenous miR-29b (Figure $5 \mathrm{~B}$ ), and the decrease of proliferation in MCF7 was also partially rescued by miR-29b-Decoy (Figure 5D, Additional file 1: Figure S5). When we orthotopically injected these cells into nude mice mammary fat pad, miR-29b overexpression repressed S100A7 induced tumor growth of MDA-MB-231 cells (Figure 6A-C), whereas miR-29b knockdown rescued tumor growth from S100A7 suppression in MCF7 cells (Figure 6D, E). Thus, we confirmed that miR-29b is the determining factor of the differential effects of S100A7 in $\mathrm{ER}^{-}$and $\mathrm{ER}^{+}$breast cancer cells.

\section{Discussion}

In the present article, we proposed a novel mechanism for the differential roles of the inflammatory protein S100A7 on the proliferation of $\mathrm{ER}^{-}$and $\mathrm{ER}^{+}$breast cancer cells. S100A7 can either promote or suppress breast cancer cell proliferation through distinct modulation of the NF- $\mathrm{kB}$ - miR-29b - p53 pathway in ER ${ }^{-}$MDA-MB231 and $\mathrm{ER}^{+}$MCF7 cells, respectively (summarized in Figure 7).

miR-29b governs numerous genes' expression by targeting their 3' UTRs, leading to both translational suppression and instability of mRNAs. Since large portions of these regulated genes are associated with cell proliferation, miR-29b has been considered as a tumor suppressor in various cancers $[14,15,19,27]$, including breast cancer 


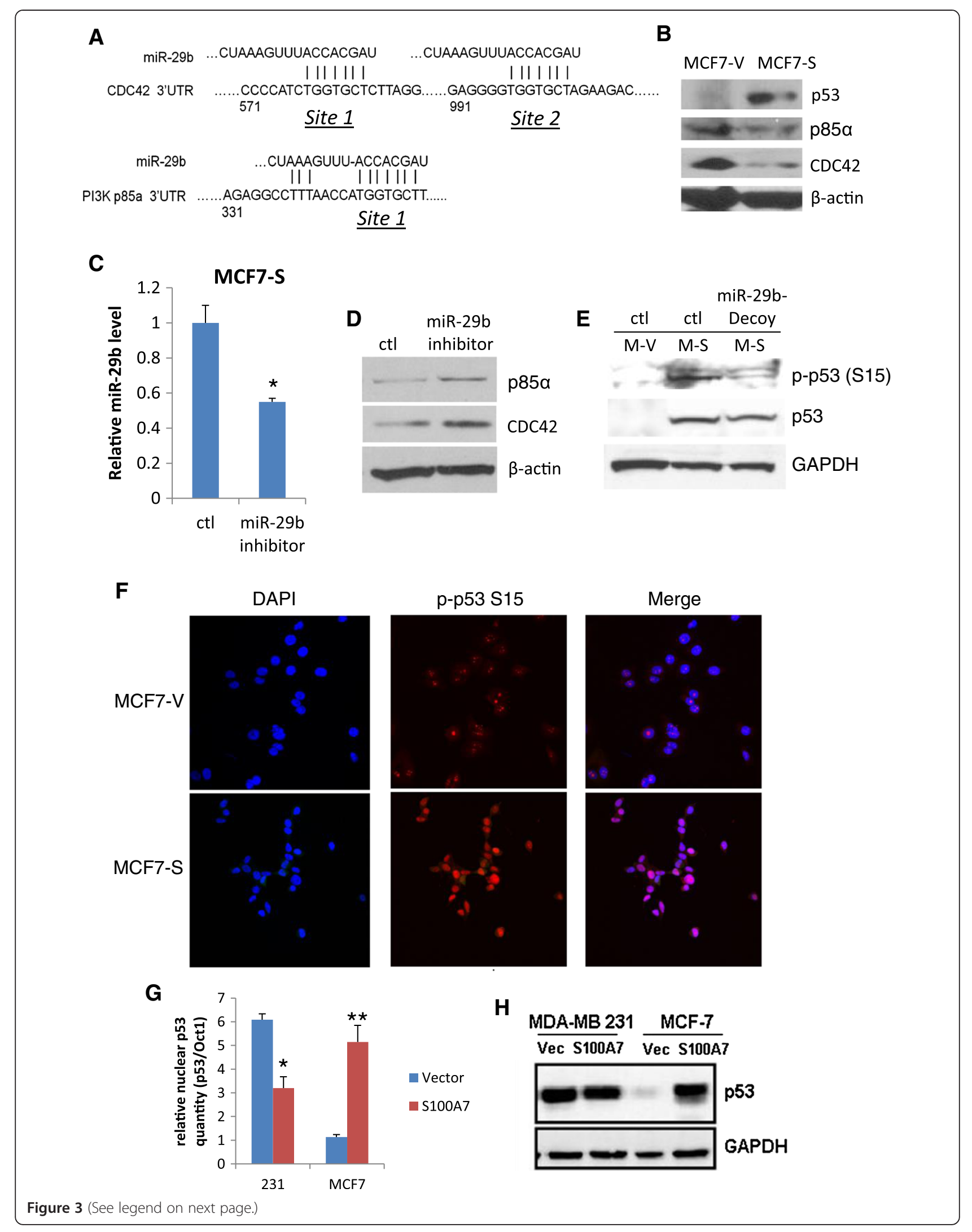


(See figure on previous page.)

Figure 3 miR-29b targets p85a and CDC42, and determines the effects of S100A7 on p53 activation and stability in different cells. (A) target sites of miR-29b on 3' UTRs of CDC42 and p85a mRNAs. (B) WB of p53, p85a and CDC42. $\beta$-actin is loading control. (C) miR-29b knockdown by antagomir inhibitor in MCF7-S cells. (D) WB of transient miR-29b inhibitor transfection partially rescuing p85a and CDC42 protein expression in MCF7-S cells. (E) prolonged knock down of miR-29b with miR-29b-Decoy reduced p53 phosphorylation and total p53 level in MCF7-S cells. (F) Confocal microscopy of phosphorylated p53 localization in MCF7-V and MCF7-S cells. Nuclei were labelled with DAPI. (G) relative p53 levels in nuclear extract of cells. p53 levels were normalized to nuclear marker Oct1. (H) total p53 levels of cells indicating the stability of p53. $\left.{ }^{*} p<0.05,{ }^{* *} p<0.01\right)$.

$[16,17]$. Moreover, other than regulation of cell proliferation, miR-29b has also been shown to inhibit breast cancer metastasis [16]. Through bioinformatic analysis and in vitro assays, we found that miR-29b expression was reduced by S100A7 in ER ${ }^{-}$MDA-MB-231 and increased by S100A7 in $\mathrm{ER}^{+} \mathrm{MCF} 7$ cells, which at least partly explained the different roles of S100A7 in regulating proliferation of different types of breast cancer cells. The clinical relevance of this was supported by patient data of the TCGA cohort, which showed that S100A7 upregulation is more likely to be associated with increased miR-29b expression in $\mathrm{ER}^{+}$breast cancer patients than $\mathrm{ER}^{-}$patients and vice versa. Interestingly, we noticed that, although S100A7 is overexpressed in both $\mathrm{ER}^{-}$and $\mathrm{ER}^{+}$breast cancer patients, there is a significant mutual-exclusivity of S100A7 and ER expression in human breast tumors (Additional file 1: Figures S1-S2). In other words, S100A7 overexpression is more commonly seen in $\mathrm{ER}^{-}$tumors. This is in agreement with previous works based on different cohorts of breast cancer patients [5].

Moreover, the differential regulation of miR-29b expression was associated with differential regulation of NF- $\mathrm{KB}$ activation by S100A7. NF-kB has been shown to either directly or indirectly inhibit the expression of miR-29b, which is transcribed from mir-29b-1 on chromosome 7 and mir-29b-2 on chromosome $1[18,19]$. Directly, NF-kB

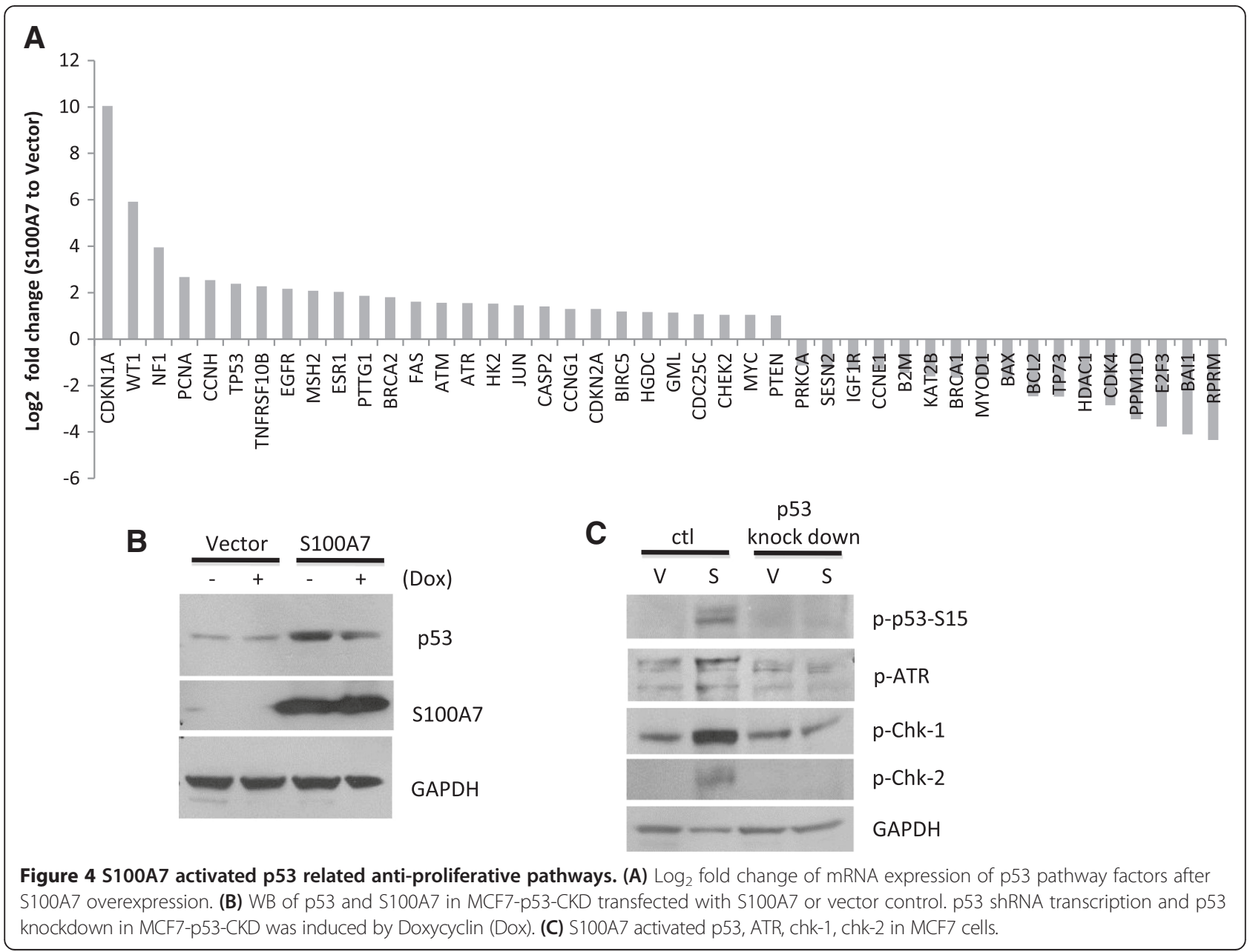



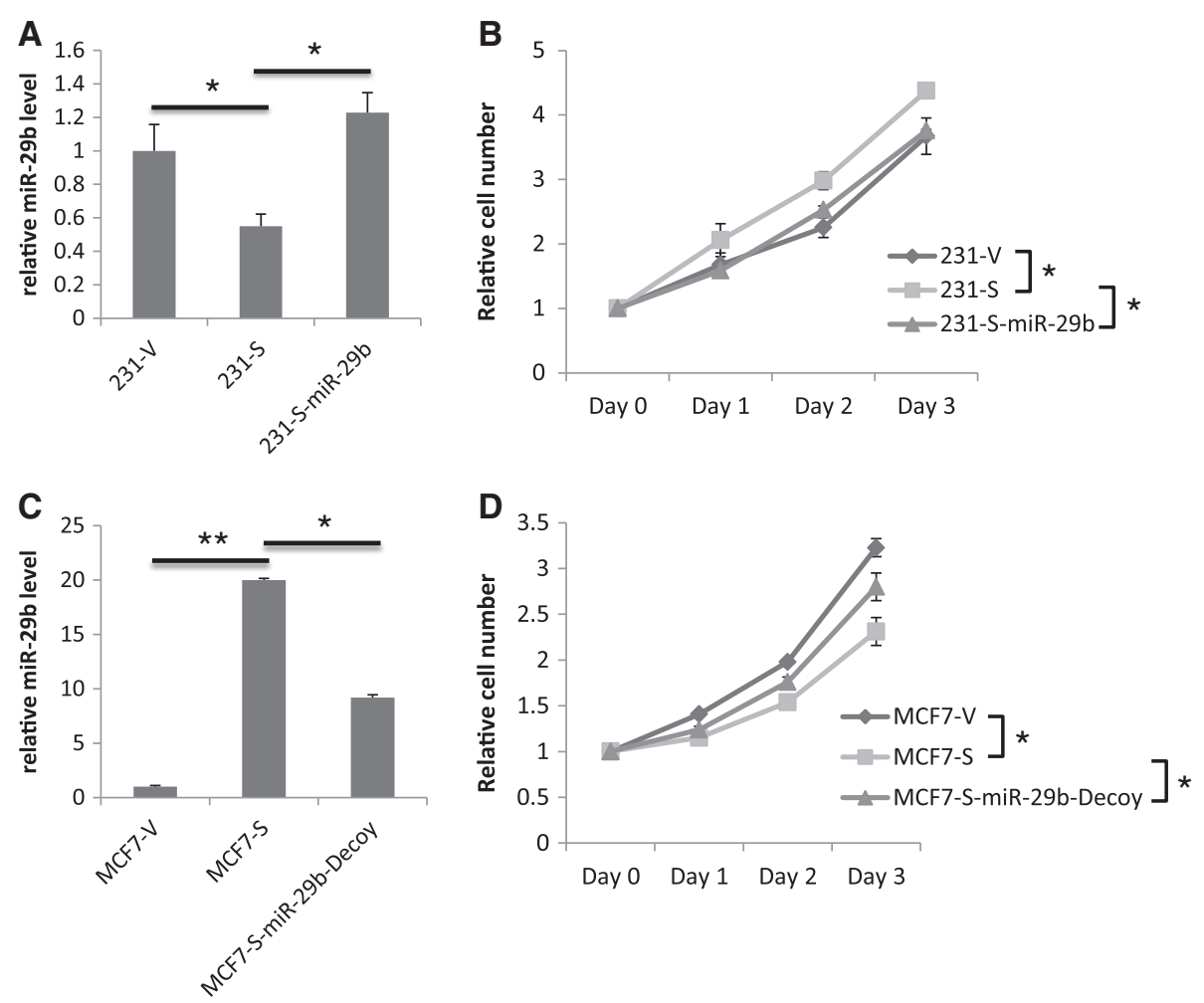

Figure 5 Manipulating miR-29b could counteract the effects of S100A7 on cell proliferation in MDA-MB-231 and MCF7. The proliferation of MDA-MB-231 and MCF7 cell lines were determined by MTT assay. (A, C) miR-29b levels of indicated cell lines. (B, D) MTT cell proliferation assays of indicated cell lines. $\left({ }^{*} p<0.05,{ }^{* *} p<0.01\right)$.

can bind to the promoter of mir-29b-1 to block its transcription. Indirectly, NF- $\mathrm{kB}$ can transactivate YY1 which then block the transcription of mir-29b-2 by binding to its promoter [19]. In the present study, we showed that S100A7 enhanced NF-kB activity in MDA-MB-231 and inhibited NF- $\mathrm{KB}$ activity in MCF7, which then directly and/or indirectly influences miR-29b transcription. It was known that ER negatively regulates activity in breast cancer [21,28-30], and may even block the transcriptional function of NF-kB [30]. Thus, the absence/presence of ER in breast cancer cells may lead to the differential regulations of NF- $\mathrm{kB}$ activation by S100A7 in MDA-MB-231 $\left(\mathrm{ER}^{-}\right)$and $\mathrm{MCF} 7\left(\mathrm{ER}^{+}\right)$cells. In this work, ER status was used as the primary standard for dividing breast cancer cells into two groups with distinct responses to S100A7. To our knowledge, the distinct regulation of NF- $\mathrm{kB}$ miR-29b by S100A7 is shown for the first time.

Among the targets of miR-29b, PI3K p $85 \alpha$ and CDC42 have been shown to be closely related to cancer growth $[22,31,32]$. And, as oncogenes, they inhibit the activation of tumor suppressor, p53 [22]. Activated p53 translocates into the nucleus and avoids degradation in the cytoplasm. Using MCF7, whose miR-29b was more significantly affected by S100A7, we showed that miR-29b targeted PI3K p85 $\alpha$ and CDC42, which consequently increased p53 level by enhancing its activation and nuclear translocation.

Activated p53 can enhance multiple anti-proliferative pathways to inhibit cancer growth [23]. Here, we showed that increased p53 activation and total protein level increased the expression of multiple p53 downstream antiproliferative factors, including mitosis checkpoint pathways and DNA repair pathways. These effects were considered to exert anti-proliferative influences to breast cancer cells.

In addition, we reversed the effects of S100A7 on cell proliferation and tumor growth by overexpressing miR$29 \mathrm{~b}$ in 231-S100A7 cells and knocking down miR-29b in MCF7-S100A7 cells, which reflected that miR-29b is not only sufficient but also necessary for determining the differential effects of S100A7 in breast cancer cells. This demonstrated that miR-29b functions downstream of S100A7 and is important in determining the differential effects of S100A7 in breast cancer cells.

In conclusion, we report a novel regulatory route that determines the pro-/anti-proliferative roles of S100A7 in $\mathrm{ER}^{-}$ and $\mathrm{ER}^{+}$breast cancer. In these different types of breast cancer cells, S100A7 differentially regulates NF-kB activation, which then differentially affects miR-29b expression 


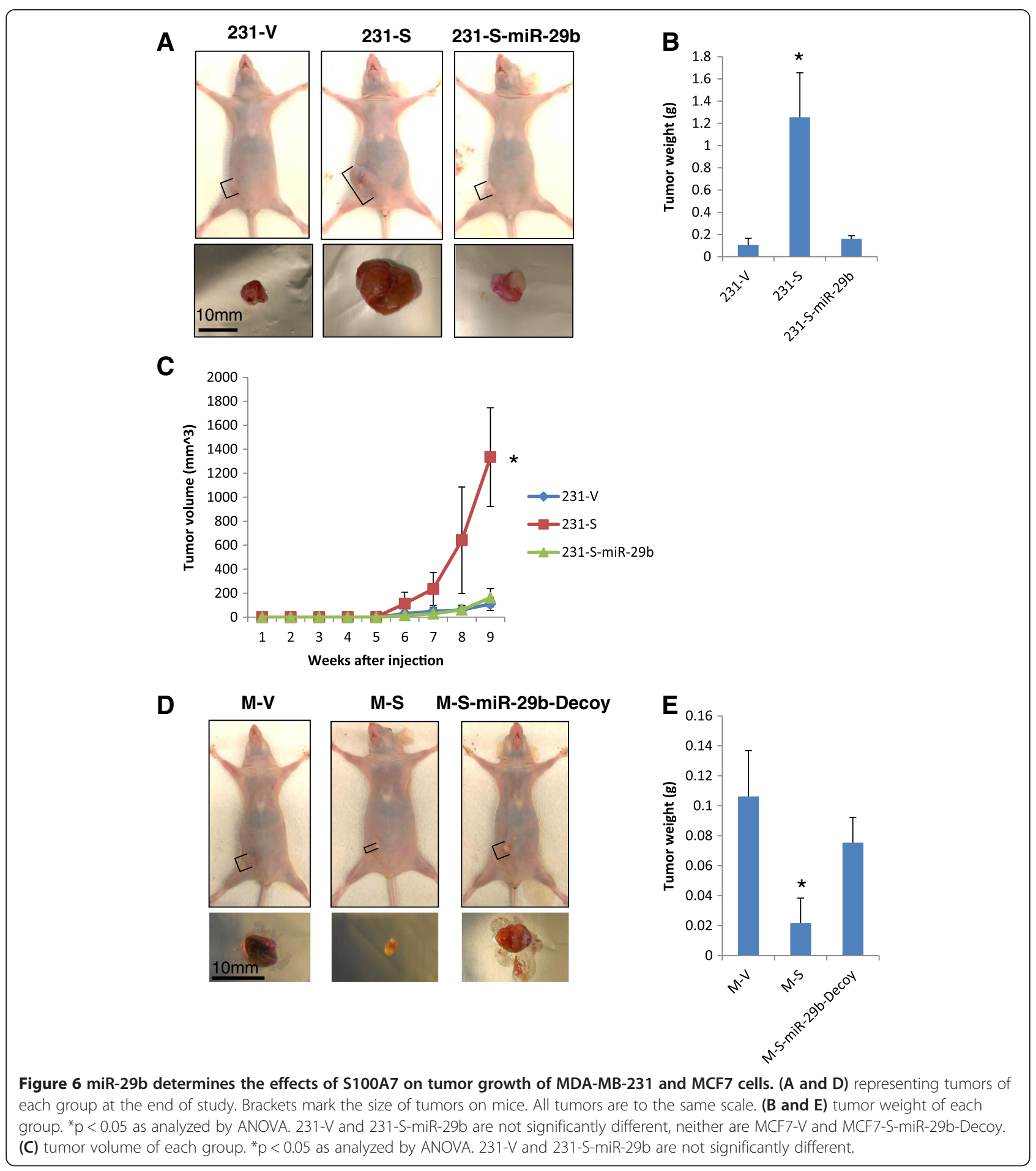

and p53 functions. And reversing miR-29b changes can suppress the effects of S100A7 in these cells. Thus, it is suggested that miR-29b may be paired with S100A7 to serve as more accurate biomarkers for breast cancer diagnosis and prognosis. On the other hand, S100A7 does not have kinase activity, which makes it difficult to be targeted with drugs.
Recently, many lipid-nanoparticle-based technologies have made it possible to target miRNAs in clinical trials of cancer treatment [33]. Hence, with the discovery of S100A7 miR-29b regulatory route, miR-29b may be potential to serve as an alternative target for S100A7 overexpression in breast cancer treatment. 


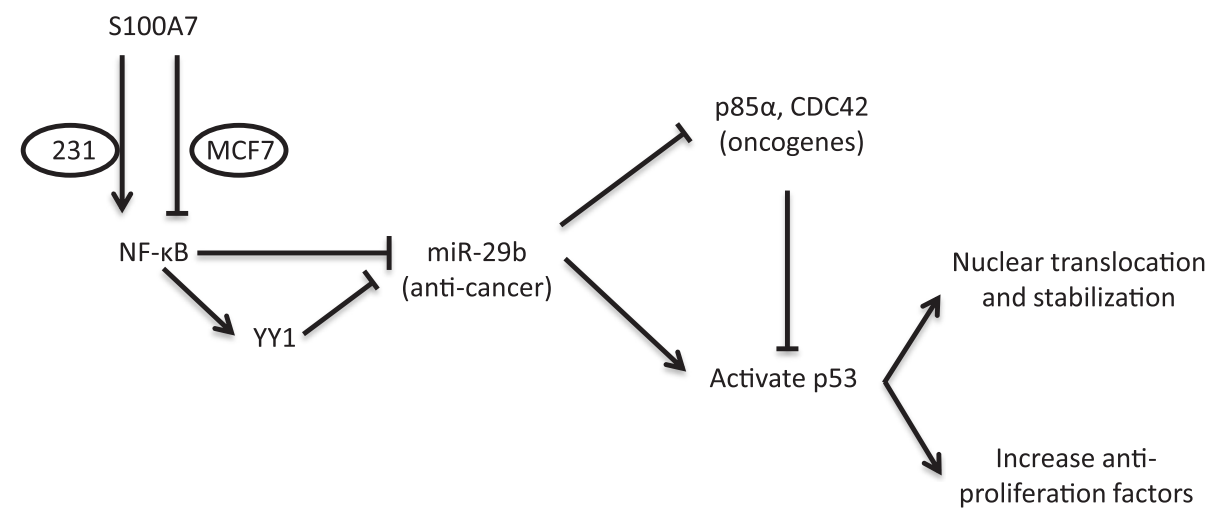

Figure 7 Proposed mechanism of differential regulations of NF-KB - miR-29b - p53 pathway by S100A7 in different types of breast cancer cells.

\section{Materials and methods Reagents and cells}

NF-кB p65, p53, PI3K p85 $\alpha$, CDC42, Oct1, $\beta$-actin and GAPDH antibodies and NF- $\mathrm{KB}$ inhibitor QNZ were purchased from Santa Cruz Biotechnology (Santa Cruz, CA). miR-29b real-time PCR assay kit and miR-29b inhibitor were purchased from Life Technologies (Carlsbad, CA). Luciferase substrate was purchased from Promega (Madison, WI). p-p53 (S15), p-ATR, p-Chk-1, p-Chk-2 antibodies were purchased from Cell Signaling Techology (Danvers, MA). S100A7 antibody was purchased from Novus Biologicals (Littleton, CO). MDA-MB-231 cell and its derivatives were cultured in DMEM medium supplemented with $10 \%$ FBS and 1\% dual antibiotics. MCF7 cell and their derivatives were cultured in MEM $\alpha$ medium supplemented with $10 \%$ FBS and 1\% dual antibiotics. p53-conditionalknockdown-MCF7 cell line was provided by Dr. Jill Bargonetti (The City University of New York). 231-S-miR29 b cell was generated by stably transfecting pcDNA3miR29b plasmid shared by Dr. Joshua Mendell (Johns Hopkins University) [34]. MCF7-S-miR-29b-Decoy cell was generated by stably transfecting AB.pCCL.sin.cPPT.U6.miR-29b-Decoy.hPGK.GFP.WPRE plasmid shared by Dr. Brian Brown (Mount Sinai School of Medicine) [35].

\section{Animal study}

Adult female nude mice (NU/NU), obtained from Charles River Laboratories (Wilmington, MA), were housed under specific pathogen-free conditions. MDA-MB-231, MCF7 or their derivatives $\left(3 \times 10^{6}\right.$ cells/200 $\mu \mathrm{L}$ PBS) were injected into the right mammary fat pad of each mouse. Mice with MCF7 cell or derivatives were also injected subcutaneously with $2.5 \mu \mathrm{g}$ of $\beta$-estradiol 17 -valerate in $50 \mu \mathrm{L}$ of Sesame oil once a week. Tumor size was assessed once a week and tumor volume was calculated using digital calipers according to the formula: volume $=$ length $\times(\text { width })^{2} / 2$. Mice were sacrificed at the end of study or per the request of the veterinarian. All mice were kept in OSU's animal facility in compliance with the guidelines and protocols approved by the IACUC.

\section{Gene functional enrichment analysis}

Gene functional enrichment (GFE) analysis is performed using the bioinformatics engine, ToppGene [36], developed by the Division of Biomedical Informatics, Cincinnati Children's Hospital Medical Center (Cincinnati, OH). Training gene list was determined by gating the significantly up-/down-regulated genes from microarray data as specified. Enrichment analysis was corrected by Bonferroni method with a p-Value cutoff of 0.05 .

\section{Quantitative reverse transcription-PCR (qRT-PCR)}

qRT-PCR was performed as previously described [37]. Briefly, total RNA was extracted from cells using TRIzol reagent (Life Technologies) and purified with RNeasy kit (Qiagen, Valencia, CA). For mRNA detection, total RNA was then reverse transcribed into cDNA using High Capacity cDNA Reverse Transcription Kit (Life Technologies) and quantified using Power SYBR Green Master Mix (Life Technologies). p53 pathway PCR array was performed using p53 Signaling Pathway RT2 Profiler PCR Array from Qiagen. For miRNA detection, total RNA was reverse transcribed and miRNAs quantified using miRNA specific realtime PCR kits from Life Technologies. Real-time PCR was performed on Eppendorf Mastercycler realplex. Data analysis was performed using standard "delta delta Ct method".

\section{NF-KB activity assays}

For the $\kappa B$-site-DNA-bait ELISA assay, nuclear and cytoplasmic extractions of cells were prepared using NE-PER Nuclear and Cytoplasmic Extraction Reagents (Thermo Scientific) per the product manual. Activated NF-kB p65 levels of both nuclear and cytoplasmic extracts were measured using TransAM NF-kB p65 Transcription Factor ELISA Kit (Active Motif, Carlsbad, CA) per the product manual. For the luciferase reporter assay, cells were 
transfected with equal amount of pNF-kB-Luc reporter plasmids by lipofectamine 2000 (Life Technologies) and harvested after $48 \mathrm{~h}$. Cells were lysed and luciferase activity was measured with the luciferase assay kit from Promega (Madison, WI) and Synergy plate reader (BioTek, Winooski, VT) per the manufacturer's manual.

\section{Confocal microscopy}

Cells grown on micro-chamber-slides were fixed and permeabilized using the Fix/Perm solution (BD Biosciences, San Jose, CA) for $20 \mathrm{~min}$ at $4^{\circ} \mathrm{C}$. The cells were washed with BD Perm/Wash buffer (BD Biosciences), and stained with respective primary antibodies for $1 \mathrm{~h}$ at $4^{\circ} \mathrm{C}$. After the incubation, cells were washed and stained with Alexa Fluor 488 or 568 secondary antibodies for $1 \mathrm{~h}$ at $4^{\circ} \mathrm{C}$. The slides were mounted using Vectashield mounting medium with DAPI (Vector Laboratories) and then imaged with Olympus FV1000 confocal microscope. The pictures were processed using Olympus FV-10 ASW software.

\section{Chromatin immunoprecipitation (ChIP)}

Cells were fixed and cross-linked in $2 \%$ paraformaldehyde, and then cross-linking was quenched with $10 \%$ volume of $1.375 \mathrm{M}$ glycine. After washing with ice cold PBS, cells were harvested and lysed with NP-40 ChIP buffer. Nuclei were isolated by centrifuge, and lysed with SDS nuclei lysis buffer. DNA was digested using Micrococcal Nuclease from New England Biolabs, and digestion was stopped by adding $50 \mathrm{mM}$ EDTA. DNA samples were then immunoprecipitated overnight at $4^{\circ} \mathrm{C}$ with NF-kB p65 antibody and Protein G/Protein A Agarose Beads (Calbiochem). After washing, DNA was eluted using SDS elution buffer, and then reverse cross-linked by incubation overnight at $65^{\circ} \mathrm{C}$. DNA was purified using TRIzol reagent (Life Technologies) and chloroform, and then subjected to PCR with specific primers.

\section{Cell proliferation assay}

Cell proliferation assay was performed using Cell Proliferation Kit I (MTT) from Roche (Indianapolis, IN) per the kit manual. Proliferation assays were done in triplicates. O.D. values were measured using Model 680 microplate reader from BIO-RAD (Hercules, CA).

\section{Western blotting (WB)}

WB was performed as previously described [37]. Briefly, proteins in cell lysates were separated by electrophoresis using NuPAGE SDS PAGE Gel (Life Technologies). Proteins transferred onto Nitrocellulose membrane were then blotted by specific primary and HRP-conjugated secondary antibodies. Protein expression was detected by Thermo ECL reagents using X-ray films.

\section{Statistical analysis}

Reported data for cell line studies are the means \pm S.E.M. of at least three independent experiments performed in duplicates or triplicates. Animal studies use $n$ $=5 \sim 8$ mice for each group. The statistical significance was determined by the Student's t test or as specified.

\section{Additional file}

Additional file 1: Supplementary figures, legends and references.

\section{Competing interests}

The authors declare that they have no competing interests.

\section{Authors' contributions}

$\mathrm{HZ}$ designed and performed the experiments, analyzed the data and wrote the manuscript. TW performed the experiments and analyzed the data. YD $\mathrm{AS}$ and $\mathrm{AG}$ performed the experiments. MB performed the experiments under instructions. MWN and RKG conceived the study and wrote the manuscript. All authors read and approved the final manuscript.

\section{Acknowledgment}

The authors would like to thank Dr. Hasan Mukhtar (University of Wisconsin) for providing the NF-KB luciferase reporter plasmid, thank Dr. Jill Bargonetti (The City University of New York) for providing the p53 CKD MCF7 cell line, thank Dr. Joshua Mendell (Johns Hopkins University) and Dr. Brian Brown (Mount Sinai School of Medicine) for sharing their miR-29b plasmids, thank the Division of Biomedical Informatics Cincinnati Children's Hospital Medical Center for providing their bioinformatic engine "ToppGene", thank Grace Amponsah for experimental assistance. This work is supported in part by NCI R01 CA153490, CA109527 and Pelotonia research fund to RKG and Pelotonia Fellowship to $\mathrm{HZ}$ and YD.

Received: 7 October 2014 Accepted: 22 December 2014 Published online: 27 January 2015

\section{References}

1. Jinquan $T$, Vorum H, Larsen CG, Madsen P, Rasmussen HH, Gesser B, et al. Psoriasin: a novel chemotactic protein. J Invest Dermatol. 1996;107:5-10.

2. Eckert RL, Broome AM, Ruse M, Robinson N, Ryan D, Lee K. S100 proteins in the epidermis. J Invest Dermatol. 2004;123:23-33.

3. Glaser R, Harder J, Lange H, Bartels J, Christophers E, Schroder JM. Antimicrobial psoriasin (S100A7) protects human skin from Escherichia coli infection. Nat Immunol. 2005;6:57-64.

4. West NR, Watson PH. S100A7 (psoriasin) is induced by the proinflammatory cytokines oncostatin-M and interleukin- 6 in human breast cancer. Oncogene. 2010:29:2083-92.

5. Al-Haddad S, Zhang Z, Leygue E, Snell L, Huang A, Niu Y, et al. Psoriasin (S100A7) expression and invasive breast cancer. Am J Pathol. 1999;155:2057-66.

6. Carlsson H, Petersson S, Enerback C. Cluster analysis of S100 gene expression and genes correlating to psoriasin (S100A7) expression at different stages of breast cancer development. Int J Oncol. 2005;27:1473-81.

7. Enerback C, Porter DA, Seth P, Sgroi D, Gaudet J, Weremowicz S, et al. Psoriasin expression in mammary epithelial cells in vitro and in vivo. Cancer Res. 2002;62:43-7.

8. Deol YS, Nasser MW, Yu L, Zou X, Ganju RK. Tumor-suppressive effects of psoriasin (S100A7) are mediated through the beta-catenin/T cell factor 4 protein pathway in estrogen receptor-positive breast cancer cells. J Biol Chem. 2011;286:44845-54.

9. Emberley ED, Niu Y, Njue C, Kliewer EV, Murphy LC, Watson PH. Psoriasin ( $\mathrm{S} 100 \mathrm{~A} 7$ ) expression is associated with poor outcome in estrogen receptor-negative invasive breast cancer. Clin Cancer Res. 2003:9:2627-31.

10. Nasser MW, Qamri Z, Deol YS, Ravi J, Powell CA, Trikha P, et al. S100A7 enhances mammary tumorigenesis through upregulation of inflammatory pathways. Cancer Res. 2012;72:604-15.

11. Krop I, März A, Carlsson H, Li X, Bloushtain-Qimron N, Hu M, et al. A putative role for psoriasin in breast tumor progression. Cancer Res. 2005;65:11326-34. 
12. Emberley ED, Niu Y, Leygue E, Tomes L, Gietz RD, Murphy LC, et al. Psoriasin interacts with Jab1 and influences breast cancer progression. Cancer Res. 2003;63:1954-61

13. Ambros V. The functions of animal microRNAs. Nature. 2004;431:350-5.

14. Garzon R, Heaphy CE, Havelange V, Fabbri M, Volinia S, Tsao T, et al. MicroRNA 29b functions in acute myeloid leukemia. Blood. 2009;114:5331-41.

15. Xiong Y, Fang JH, Yun JP, Yang J, Zhang Y, Jia WH, et al. Effects of microRNA-29 on apoptosis, tumorigenicity, and prognosis of hepatocellular carcinoma. Hepatology. 2010;51:836-45.

16. Chou J, Lin JH, Brenot A, Kim JW, Provot S, Werb Z. GATA3 suppresses metastasis and modulates the tumour microenvironment by regulating microRNA-29b expression. Nat Cell Biol. 2013;15:201-13.

17. Wu Z, Huang X, Zou Q, Guo Y. The inhibitory role of Mir-29 in growth of breast cancer cells. J Exp Clin Cancer Res. 2013;32:98.

18. Mott JL, Kurita S, Cazanave SC, Bronk SF, Werneburg NW, Fernandez-Zapico ME. Transcriptional suppression of mir-29b-1/mir-29a promoter by c-Myc, hedgehog, and NF-kappaB. J Cell Biochem. 2010;110:1155-64.

19. Wang H, Garzon R, Sun H, Ladner KJ, Singh R, Dahlman J, et al. NF-kappaB-YY1miR-29 regulatory circuitry in skeletal myogenesis and rhabdomyosarcoma. Cancer Cell. 2008;14:369-81.

20. Baud V, Karin M. Is NF-kappaB a good target for cancer therapy? Hopes and pitfalls. Nat Rev Drug Discov. 2009:8:33-40.

21. Sas L, Lardon F, Vermeulen PB, Hauspy J, Van Dam P, Pauwels P, et al. The interaction between ER and NFKB in resistance to endocrine therapy. Breast Cancer Res. 2012;14:212.

22. Park SY, Lee JH, Ha M, Nam JW, Kim VN. miR-29 miRNAs activate p53 by targeting p85 alpha and CDC42. Nat Struct Mol Biol. 2009;16:23-9.

23. Vousden KH, Lu X. Live or let die: the cell's response to p53. Nat Rev Cancer. 2002;2:594-604.

24. Network CGA. Comprehensive molecular portraits of human breast tumours. Nature. 2012;490:61-70.

25. Ma F, Xu S, Liu X, Zhang Q, Xu X, Liu M, et al. The microRNA miR-29 controls innate and adaptive immune responses to intracellular bacterial infection by targeting interferon-gamma. Nat Immunol. 2011;12:861-9.

26. Brekman A, Singh KE, Polotskaia A, Kundu N, Bargonetti J. A p53independent role of $\mathrm{Mdm} 2$ in estrogen-mediated activation of breast cancer cell proliferation. Breast Cancer Res. 2011;13:R3.

27. Balkhi MY, Iwenofu OH, Bakkar N, Ladner KJ, Chandler DS, Houghton PJ, et al. miR-29 acts as a decoy in sarcomas to protect the tumor suppressor A20 mRNA from degradation by HuR. Sci Signal. 2013;6:ra63.

28. Biswas DK, Cruz AP, Gansberger E, Pardee AB. Epidermal growth factorinduced nuclear factor kappa B activation: a major pathway of cell-cycle progression in estrogen-receptor negative breast cancer cells. Proc Natl Acad Sci U S A. 2000;97:8542-7.

29. Parker JS, Mullins M, Cheang MC, Leung S, Voduc D, Vickery T, et al. Supervised risk predictor of breast cancer based on intrinsic subtypes. J Clin Oncol. 2009;27:1160-7.

30. Cvoro A, Tzagarakis-Foster C, Tatomer D, Paruthiyil S, Fox MS, Leitman DC. Distinct roles of unliganded and liganded estrogen receptors in transcriptional repression. Mol Cell. 2006;21:555-64.

31. Lang N, Liu M, Tang QL, Chen X, Liu Z, Bi F. Effects of microRNA-29 family members on proliferation and invasion of gastric cancer cell lines. Chin J Cancer. 2010;29:603-10.

32. Namløs HM, Meza-Zepeda LA, Barøy T, Østensen IH, Kresse SH, Kuijjer ML, et al. Modulation of the osteosarcoma expression phenotype by microRNAs. PLoS One. 2012;7:e48086.

33. Kanasty R, Dorkin JR, Vegas A, Anderson D. Delivery materials for siRNA therapeutics. Nat Mater. 2013;12:967-77.

34. Hwang HW, Wentzel EA, Mendell JT. A hexanucleotide element directs microRNA nuclear import. Science. 2007;315:97-100.

35. Mullokandov G, Baccarini A, Ruzo A, Jayaprakash AD, Tung N, Israelow B, et al. High-throughput assessment of microRNA activity and function using microRNA sensor and decoy libraries. Nat Methods. 2012;9:840-6.

36. Chen J, Bardes EE, Aronow BJ, Jegga AG. ToppGene Suite for gene list enrichment analysis and candidate gene prioritization. Nucleic Acids Res. 2009;37:W305-11.

37. Anand AR, Zhao H, Nagaraja T, Robinson LA, Ganju RK. N-terminal Slit2 inhibits HIV-1 replication by regulating the actin cytoskeleton. Retrovirology. 2013;10:2

\section{Submit your next manuscript to BioMed Central and take full advantage of:}

- Convenient online submission

- Thorough peer review

- No space constraints or color figure charges

- Immediate publication on acceptance

- Inclusion in PubMed, CAS, Scopus and Google Scholar

- Research which is freely available for redistribution

Submit your manuscript at www.biomedcentral.com/submit 